\title{
SOD1 Is Essential for the Viability of DT40 Cells and Nuclear SOD1 Functions as a Guardian of Genomic DNA
}

\author{
Eri Inoue, ${ }^{1}$ Keizo Tano, ${ }^{2}$ Hanako Yoshii, ${ }^{2}$ Jun Nakamura, ${ }^{3}$ Shusuke Tada, ${ }^{1}$ \\ Masami Watanabe, ${ }^{2}$ Masayuki Seki, ${ }^{1}$ and Takemi Enomoto ${ }^{1,4}$ \\ ${ }^{1}$ Molecular Cell Biology Laboratory, Graduate School of Pharmaceutical Sciences, \\ Tohoku University, Aoba 6-3, Aramaki, Aoba-ku, Sendai 980-8578, Japan \\ ${ }^{2}$ Research Reactor Institute, Kyoto University, Kumatori 590-0494, Japan \\ ${ }^{3}$ Department of Environmental Sciences and Engineering, University of North Carolina at Chapel Hill, \\ Chapel Hill, NC 27599, USA \\ ${ }^{4}$ Research Institute of Pharmaceutical Sciences, Faculty of Pharmacy, Musashino University, \\ 1-1-20 Shinmachi, Nishitokyo-shi, Tokyo 202-8585, Japan
}

Correspondence should be addressed to Masayuki Seki, seki@mail.pharm.tohoku.ac.jp and

Takemi Enomoto, t_eno@musashino-u.ac.jp

Received 19 April 2010; Accepted 4 June 2010

Academic Editor: Shigenori Iwai

Copyright (C) 2010 Eri Inoue et al. This is an open access article distributed under the Creative Commons Attribution License, which permits unrestricted use, distribution, and reproduction in any medium, provided the original work is properly cited.

Reactive oxygen species (ROSs) are produced during normal cellular metabolism, particularly by respiration in mitochondria, and these ROSs are considered to cause oxidative damage to macromolecules, including DNA. In our previous paper, we found no indication that depletion of mitochondrial superoxide dismutase, SOD2, resulted in an increase in DNA damage. In this paper, we examined SOD1, which is distributed in the cytoplasm, nucleus, and mitochondrial intermembrane space. We generated conditional SOD1 knockout cells from chicken DT40 cells and analyzed their phenotypes. The results revealed that SOD1 was essential for viability and that depletion of SOD1, especially nuclear SOD1, increased sister chromatid exchange (SCE) frequency, suggesting that superoxide is generated in or near the nucleus and that nuclear SOD1 functions as a guardian of the genome. Furthermore, we found that ascorbic acid could offset the defects caused by SOD1 depletion, including cell lethality and increases in SCE frequency and apurinic/apyrimidinic sites.

\section{Introduction}

Superoxide is produced during normal cellular metabolism, particularly by respiration in mitochondria, and reactive oxygen species (ROSs) derived from superoxide are considered to cause oxidative damage to macromolecules including DNA $[1,2]$. Superoxide dismutases (SODs) convert superoxide into hydrogen peroxide and molecular oxygen [3]. SODs are classified into three species in vertebrate cells: copper- and zinc-dependent SOD or SOD1, manganesedependent SOD or SOD2, and copper-dependent SOD or SOD3 [4]. SOD1 is present in the cytoplasm, the nucleus, and the intermembrane space of mitochondria [5-7], SOD2 is present in the mitochondrial matrix $[8,9]$, and SOD3 is a secreted protein found in the extracellular matrix of tissues $[4,10]$.

The importance of SOD2 in organisms has been clearly shown with Sod2 knockout mice. In one case, Sod2 knockout mice survived only up to three weeks of age and exhibited several novel pathologic phenotypes, including severe anemia, degeneration of neurons, and progressive motor disturbances [11]. Moreover, the Sod2 knockout mice older than seven days exhibited extensive mitochondrial injury within degenerating neurons and cardiac myocytes. In the second case of Sod2 knockout, mice were born alive but died within ten days with severe cardiomyopathy [12]. In our previous study, we investigated the events occurring shortly after the loss of SOD2 in vertebrate 
cells by generating conditional SOD2 knockout cells using chicken DT40 cells [13]. By monitoring the frequency of sister chromatid exchange (SCE), a very sensitive assay for detecting DNA lesions [14], we found that depletion of SOD2 had no impact on the integrity of genomic DNA.

In the case of SOD1, high levels of SOD1 have been detected in the central nervous system, liver, and kidney in mammals. In some cases, SOD1 is referred to as cytoplasmic SOD because of its high distribution in the cytoplasm, but it is also detected in cellular organelles including nucleus $[5,6]$. Recent studies show that SOD1 may act as a nuclear protein as well. SOD1 interacts with estrogen receptor $\alpha(\mathrm{ER} \alpha)$, a ligand-activated transcription factor, and influences the expression of estrogen responsive genes [15]. Moreover, since it is reported that SOD1-deficient mice show increased mutagenesis and cancer risk $[16,17]$, it seems likely that SOD1 functions in the nucleus besides the regulation of transcription. However, little attention has been paid to the role of SOD1 in the nucleus, especially as a guardian of the genome.

In this study, we generated conditional SOD1 knockout cells from DT40 cells and examined their phenotypes. Our results indicated that SOD1 is essential for viability in DT40 cells, and that nuclear SOD1 functions as a guardian of the genome by scavenging superoxide generated in or near the nucleus.

\section{Materials and Methods}

2.1. Plasmid Construction. DNA containing SOD1 exons I$\mathrm{V}$ was obtained by PCR from DT40 genomic DNA using the Easy-DNA Kit (Invitrogen, Carlsbad, California, USA) and Ex-Taq polymerase (Takara Bio Inc., Otsu, Shiga, Japan). The chicken targeting constructs for SOD1, SOD1-blastcidin ${ }^{\mathrm{r}}$ and SOD1-puromycin ${ }^{\mathrm{r}}$, were made by replacing the exons I-III with blastcidin (Bsr) or puromycin (Puro) selection marker cassette. To construct an expression plasmid carrying a human SOD1 cDNA with the tet-off promoter (hSOD1), the human SOD1 cDNA was obtained by reverse transcriptionPCR (RT-PCR) from HeLa cells using SuperScript III Reverse Transcriptase (Invitrogen) and inserted into the pUHG 10-3 vector [18].

To construct a plasmid carrying a localization signal combined with hSOD1, hSOD1 cDNA alone, or hSOD1 cDNA combined with either nuclear localization signal (NLS) derived from SV40 large tumor antigen or nuclear export signal (NES) derived from chicken, HDAC3 [19] was inserted into the EGFP-C1 vector (BD Biosciences, San Jose, California, USA).

2.2. Cell Culture. Cells were cultured in Roswell Park Memorial Institute medium (RPMI)1640 supplemented with 10\% fetal bovine serum, $1 \%$ chicken serum, and $100 \mu \mathrm{g} / \mathrm{mL}$ kanamycin at $39^{\circ} \mathrm{C}$. To generate a growth curve, cells $(1 \times$
$10^{5}$ ) were inoculated and cultured at $39^{\circ} \mathrm{C}$ for the specified time periods, and the number of cells was counted in a representative field using a Bürker-Türk line counting chamber. Ascorbic acid phosphoric ester magnesium salt (APM) (Wako Pure Chemical Industries Ltd., Osaka, Japan) was dissolved in phosphate buffered saline (PBS; $137 \mathrm{mM}$ $\mathrm{NaCl}, 2.68 \mathrm{mM} \mathrm{KCl}, 8.04 \mathrm{mM} \mathrm{Na} \mathrm{HPO}_{4}$, and $1.47 \mathrm{mM}$ $\left.\mathrm{KH}_{2} \mathrm{PO}_{4}\right)$ and then diluted with culture medium at the time of assay.

2.3. Gene Disruption. For gene targeting, DT40 cells $(1 \times$ $10^{7}$ ) were electroporated with a Gene Pulser (BioRad, Hercules, California, USA) at $550 \mathrm{~V}$ and $25 \mu \mathrm{F}$ in the presence of $30 \mu \mathrm{g}$ linearized targeting constructs. Drug-resistant colonies were selected in 96-well plates with medium containing $30 \mu \mathrm{g} / \mathrm{mL}$ blasticidin S or $0.5 \mu \mathrm{g} / \mathrm{mL}$ puromycin. Gene disruption was confirmed by Southern blotting, genomic PCR, and RT-PCR.

2.4. Southern Blotting. Southern blotting was performed according to the manual of Rediprime II Random Prime Labelling System (GE Healthcare UK Ltd. Amersham Place, Little Chalfont, Buckinghamshire, UK). Genomic DNA $(40 \mu \mathrm{g})$ was digested with $N d e \mathrm{I}$, separated in a $1 \%$ agarose gel, transferred to a nylon membrane (GE Healthcare UK Ltd.) using $20 \times$ standard saline citrate $(20 \times \mathrm{SSC} ; 3 \mathrm{M} \mathrm{NaCl}$, $0.3 \mathrm{M}$ sodium citrate), and then hybridized with the $771 \mathrm{bp}$ ${ }^{32} \mathrm{P}$-labeled probe indicated in Figure 1(b).

2.5. Western Blotting. Cells that had been cultured in the presence or absence of doxycycline (Dox), a derivative of tetracycline, for $0,24,48,72$, and 96 hours were harvested, washed with PBS, precipitated, and suspended in SDS sample buffer (50 mM Tris- $\mathrm{HCl}$ ( $\mathrm{pH}$ 6.8), 10\% glycine, 2\% SDS, $0.1 \%$ bromophenol blue and 0.1 M DTT). Samples prepared from $7.5 \times 10^{4}$ cells were fractionated in a linear $4 \%$ to $14 \%$ gradient SDS-polyacrylamide gel. Proteins were transferred onto a Immun-Blot PVDF Membrane (BioRad) and immunoblotted with primary antibodies (anti-Cu/Zn Superoxide Dismutase (Assay Designs, Inc., Ann Arbor, Michigan, USA), anti-LaminB1 (Invitrogen), anti- $\alpha$-tubulin (SigmaAldrich, St. Louis, Missouri, USA), and anti- $\beta$-actin (SigmaAldrich), followed by a horseradish peroxidase-conjugated antirabbit or antimouse IgG secondary antibody (New England Biolabs, Ipswich, Massachusetts, USA). Bands were visualized using enhanced chemiluminescence (ECL) (GE Healthcare).

2.6. Cell Cycle Analysis. Cells were prepared using the CycleTEST PLUS DNA Reagent Kit (Becton Dickinson, Franklin Lakes, New Jersey, USA). Subsequent flowcytometric analysis was performed with FACScan (Becton Dickinson). Data were analyzed using CellFIT software (Becton Dickinson).

2.7. Superoxide Assay. Intracellular generation of ROS was detected by BES-So-AM (Wako Pure Chemical Industries Ltd.), a highly specific fluorescent probe for superoxide [20]. 


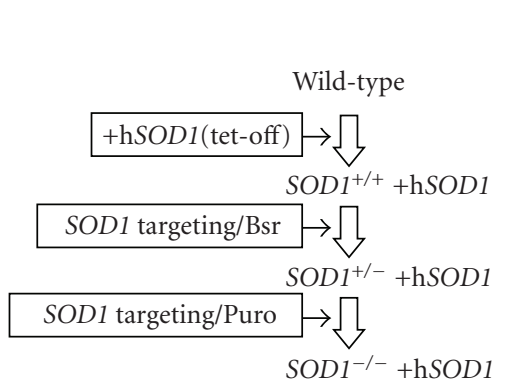

(a)

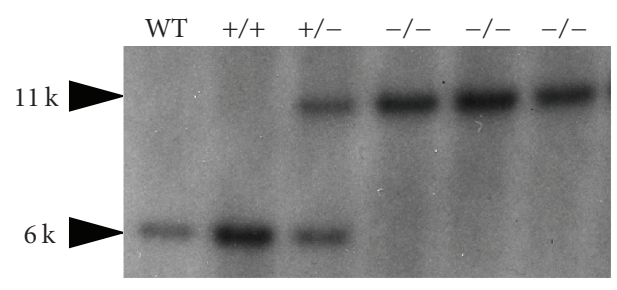

(c)
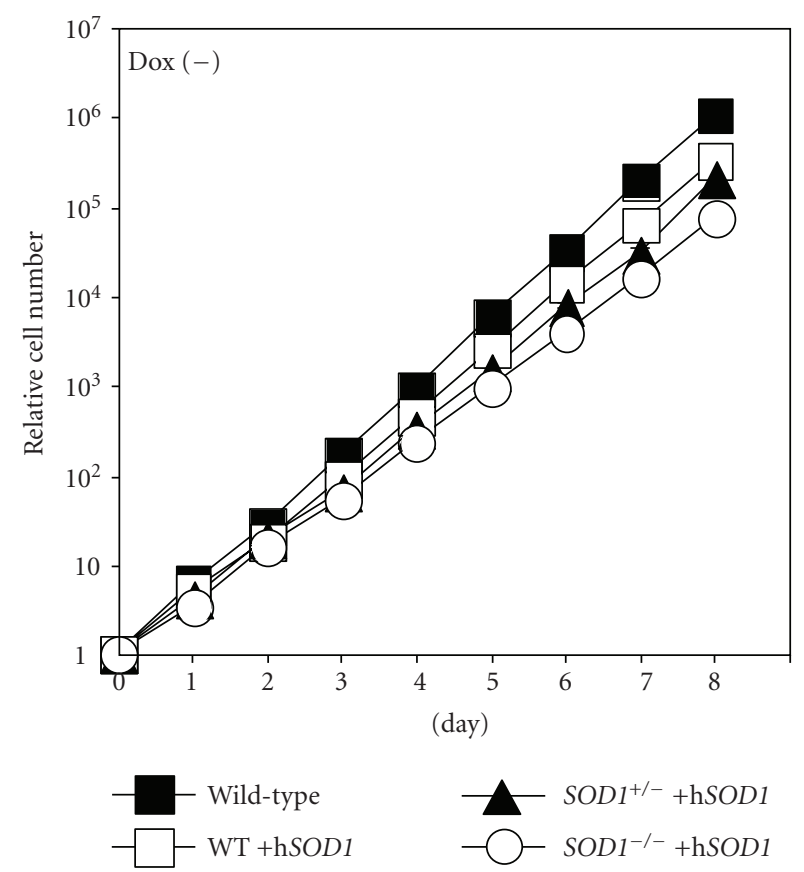

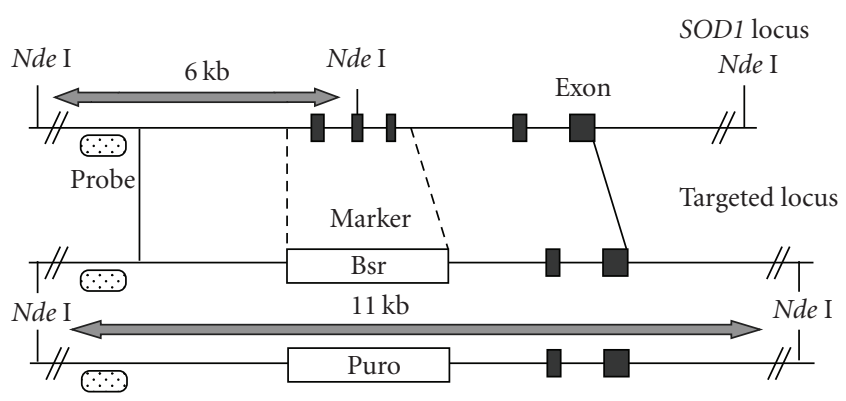

(b)

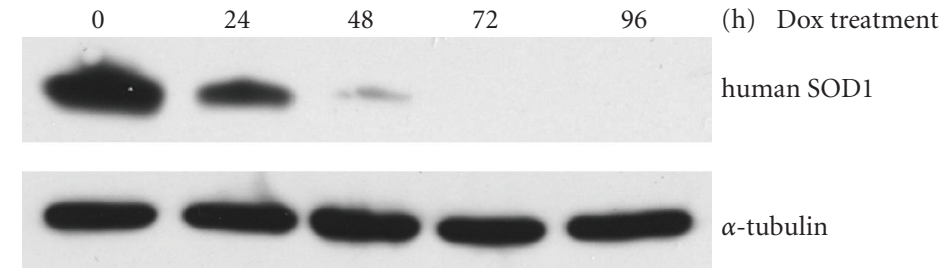

(d)

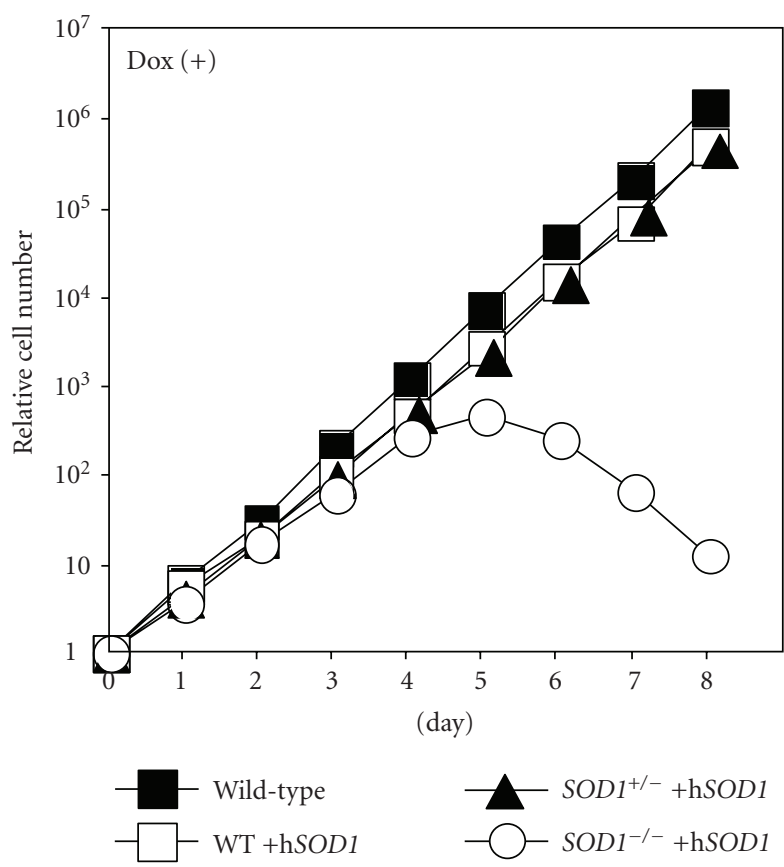

(e)

FIGURE 1: Generation of SOD1 $1^{-/-}$cells expressing human SOD1 from the tet-off promoter. (a) Schematic representation of the generation of DT40 SOD $1^{-1-}+$ hSOD1 cells. (b) Schematic representation of the SOD1 genomic locus and configuration of the targeted locus. (c) Southern blot analysis for the confirmation of the status of the SOD1 wild-type (WT), WT + human SOD1 (+/+), heterozygous (+/-), and homozygous (-I-) cells, using NdeI digested genomic DNA and the probe indicated in (b). (d) Dox-dependent disappearance of human SOD1, as confirmed by western blot analysis, with $\alpha$-tubulin used as the loading control. (e) Growth curves of indicated genotype cells. Indicated mutant cells were cultured in the presence or absence of $1 \mu \mathrm{g} / \mathrm{mL}$ Dox. Dox had no effect on the growth or viability of wild-type cells.

The agent was dissolved in dimethyl sulfoxide and diluted with culture medium at the time of assay. Cells were treated with $5 \mu \mathrm{M}$ (final concentration) BES-So-AM for $20 \mathrm{~min}$. After washing twice with PBS, the cells were suspended in $\mathrm{PBS}$, and fluorescent intensity was measured using FACScan (Becton Dickinson).
2.8. Measurement of Sister Chromatid Exchange. To measure the frequency of sister chromatid exchange (SCE), cells (1 $2 \times 10^{6}$ ) were cultured for two cycle periods in medium containing $10 \mu \mathrm{M}$ BrdU with or without paraquat (SigmaAldrich) and pulsed with $0.1 \mu \mathrm{g} / \mathrm{mL}$ colcemid (Wako Pure Chemical Industries Ltd.) for 2 hours. The cells were 
harvested and treated with $75 \mathrm{mM} \mathrm{KCl}$ for $18 \mathrm{~min}$ at room temperature and then fixed with methanol-acetic acid $(3: 1)$ for $30 \mathrm{~min}$. The cell suspension was then dropped onto icecold wet glass slides and air-dried. The cells on the slides were incubated with $10 \mu \mathrm{g} / \mathrm{mL}$ Hoechst 33258 in phosphate buffer ( $\mathrm{pH}$ 6.8) for $20 \mathrm{~min}$ and rinsed with MacIlvaine solution (164 $\mathrm{mM} \mathrm{Na}_{2} \mathrm{HPO}_{4}, 16 \mathrm{mM}$ citric acid, $\mathrm{pH}$ 7.0). The cells were then exposed to black light $(\lambda=352 \mathrm{~nm})$ at a distance of $1 \mathrm{~cm}$ for $20 \mathrm{~min}$, incubated in 2X SSC $(0.3 \mathrm{M} \mathrm{NaCl}, 0.03 \mathrm{M}$ sodium citrate) at $58^{\circ} \mathrm{C}$ for $20 \mathrm{~min}$, and then stained with $3 \%$ Giemsa solution for $20 \mathrm{~min}$.

2.9. Aldehyde Reactive Probe (ARP) Slot Blot Analysis. AP sites were measured as previously described in [21] by aldehyde reactive probe (ARP, Dojindo Molecular Technology, Gaithersburg, MD, USA) labeling and slot blot (PMID: 9443396).

\section{Results}

3.1. Generation of Conditional SOD1-Knockout Cells. To investigate the events occurring shortly after depletion of SOD1, we generated cells in which the expression of the SOD1 gene could be turned off by Dox treatment, using chicken DT40 cells. First, DT40 wild-type cells were transfected with a plasmid expressing a human SOD1 cDNA driven by the tet-off promoter (Figure 1(a)). Then, SOD1 genes were disrupted as shown in Figure 1(b). Disruption was confirmed by Southern blotting (Figure 1(c)) using the probe shown in the Figure 1(b). Treatment of these cells with Dox suppressed expression of the hSOD1 protein (Figure $1(\mathrm{~d})$ ). The hSOD1 protein level reached a limit of detection at 96 hours after Dox addition as measured by western blotting, even in the case of overexposure (data not shown).

Even in the absence of Dox, the growth rate of SOD $1^{-/-}+$hSOD1 cells was slightly lower than that of wild-type cells. Although fibroblasts derived from the SOD1 knockout mouse are reportedly viable [22], the SOD1 gene knockout DT40 cells developed in this study died after depletion of SOD1. As mentioned above, hSOD1 disappeared within 96 hours after Dox addition, and cells ceased exponential growth on the 5 th day and died soon after (Figure 1(e)).

3.2. Analyses of Cell Death in SOD1-Depleted Cells. We next analyzed the mode of cell death of hSOD1-depleted cells. Flow cytometric analysis showed that hSOD1-depleted cells died gradually without arresting in a specific phase of the cell cycle (Figure 2(a)). Microscopic observation revealed the appearance of apoptotic bodies (Figure 2(b)). In agreement with this observation, cleavage of the apoptotic marker lamin B1 was detected from two days after Dox addition (Figure 2(c)). Interestingly, five days after Dox addition, the proportion of cells in the $M$ phase decreased, with a concomitant increase in the number of cells with "hypercondensed chromatin" (Figure 2(b)), resembling the hypercondensed chromatin, that appears in colcemid-treated cells arrested for long periods in the M phase [23].

3.3. Depletion of SOD1 Increases Superoxide Levels and Affects Genome Integrity. To understand the influence of hSOD1 depletion on the level of superoxide in the cell, intracellular levels of superoxide were measured using BES-So-AM, a fluorescent probe used to detect cell-derived superoxide with high selectivity [20]. The intracellular level of superoxide in the hSOD1-depleted cells cultured in the presence of Dox for 108 hours was twofold higher than that in the SOD $1^{-/-}+$hSOD1 cells expressing hSOD1 (Figure 3(a)).

Since SOD1 reportedly exists in the nucleus, we next addressed its possible function in genome integrity. When DNA damage occurs, under normal conditions, the genome is repaired immediately and properly using appropriate DNA repair pathways. When cells are treated with DNA damaging agents such as Mitomycin C or UV irradiation, elevated sister chromatid exchange (SCE) frequencies can be observed at much lower doses of the agents than those to cause lethality because some DNA repair pathways include recombination processes $[14,24,25]$. Therefore, SCE is considered a very sensitive indicator of the existence of DNA lesions. SCE frequencies were measured to detect whether or not SOD1 participates in protecting DNA from attack from superoxide. SCE frequency in hSOD1-depleted cells cultured in the presence of Dox for 120 hours was increased approximately fourfold compared with that in hSOD1-expressing cells (Figure 3(b)).

Oxidative DNA damage is repaired mainly by a baseexcision repair pathway that generates apurinic/apyrimidinic (AP) sites during its repair process [26]. Therefore, an increase in AP sites indicates an increase in oxidative DNA damage. As shown in Figure 3(c), the number of AP sites in SOD1-depleted cells was about twofold that in hSOD1expressing cells. These phenotypes observed in SOD1depleted cells, elevated SCE frequency and increased AP sites suggest that SOD1 could serve to provide protection for genomic DNA against ROS.

3.4. Ascorbic Acid Offsets the Absence of SOD1. Defense mechanisms against oxidative stress caused by ROS involve both enzymatic and nonenzymatic antioxidants. Ascorbic acid is a representative non-enzymatic antioxidant and its phosphoric ester magnesium salt (APM) is known to exert anti-mutagenic effects by scavenging organic radicals [27, 28].

The phenomena observed in SOD1-depleted cells seem to be caused directly or indirectly by the increase in superoxide, but do not appear to be due to the depletion of SOD1 protein itself. To test this, SOD1-depleted cells were cultured in the presence of APM (Figure 4(a)). SOD1depleted cells proliferated normally in the presence of APM, and no growth defect was observed after culturing cells longer than 10 days (data not shown). It must be noted that the suppression of expression of SOD1 by Dox is not affected by APM addition (Figure 4(a); lower panel). The superoxide level in the cells cultured in the presence of Dox, 
but also with APM for $108 \mathrm{~h}$, was reduced to the level of the cells expressing hSOD1 (Figure 3(a)). Furthermore, APM completely compensated for depletion of SOD1 with regard to the number of AP sites and SCE frequency (Figures 3(c) and $4(\mathrm{~b}))$.

\subsection{Nuclear Localization of SOD1 Is Important for Its Function} in Reducing DNA Lesions. Mitochondria are the major superoxide-producing organelles in the cell and contain an intrinsic SOD, SOD2. In our previous study, we found that depletion of SOD2 had no impact on SCE frequency. It is possible that superoxide produced in or near the nucleus could cause DNA lesions, and that SOD1 in the nucleus could therefore reduce these lesions. To confirm the above possibility, we generated cells expressing hSOD1 fused with a nuclear localization signal (NLS) or nuclear export signal (NES) and green fluorescent protein (GFP) for visualization. The expression vectors GFP-NLS-hSOD1, GFP-NES-hSOD1, and GFP-hSOD1 were transfected into $S O D 1^{-1-}+$ hSOD1 cells. Their expression and localization were confirmed by GFP, which tagged the N-terminal of hSOD1 (Figure 5(a)). The hSOD1 without localization signals was distributed throughout the cell. In contrast, the hSOD1 fused with NLS was found mainly in the nucleus and the hSOD1 fused with NES was found mainly in the cytoplasm. Although, in the presence of Dox, cells expressing NLS-hSOD1 or NES-hSOD1 grew slightly slower than the cells expressing hSOD1, NLS-hSOD1 and NES-hSOD1 did suppress lethality (Figure 5(b)).

To test whether DNA damage could be increased by excluding nuclear SOD1, SCE frequency was measured in the cells expressing NES-hSOD1 as well as the cells expressing NLS-hSOD1 or hSOD1 without any localization signal. As mentioned above, the SOD2 $2^{-/-}+$hSOD2 cells did not show any difference in SCE frequency between Doxtreated and untreated cells (Figure 5(c)). Cells expressing NES-hSOD1 showed a slight increase in SCE frequency in the presence of Dox while cells expressing NLS-hSOD1 or hSOD1 showed no difference in SCE frequency in the presence or absence of Dox. The limited increase in SCE frequency in the cells expressing NES-hSOD1 compared with that in SOD1-depleted cells may be due to the incomplete exclusion of SOD1 from the nucleus (Figure 5(a)). The importance of nuclear SOD1 for protecting DNA from lesions was more clearly shown when these cells were treated with a superoxide-generating agent, paraquat. As shown in Figure 5(d), the cells expressing NES-hSOD1 showed a prominent increase in SCE frequency in the presence of Dox, but the cells expressing NLS-hSOD1 or hSOD1 did not.

\section{Discussion}

In this study, we analyzed the phenotypes of conditional SOD1 knockout cells after depletion of SOD1 in order to understand the cellular functions of SOD1. We found that SOD1 was essential for viability and that nuclear SOD1 protected the genome. In addition, we found that ascorbic acid recovered cell viability and suppressed increases in SCE frequency and AP sites, two phenotypes observed in SOD1depleted cells.

The lethality of the SOD1-depleted cells seems to conflict with the previous observation that an SOD1 knockout mouse is viable, albeit with a shortened life span $[29,30]$. This conflict could be explained as follows. The detrimental effects seen in the SOD1 knockout mouse caused by SOD1 depletion could have been opposed by the effects of other antioxidants, including ascorbic acid, which the mouse produces in the liver [31] in sufficient quantities for the retention of viability. In addition, the concentration of oxygen in the tissues or cells in vivo is much lower than that in the cell cultures. In fact, lowering the oxygen concentration in the cell cultures partially retarded the lethality in SOD1-depleted DT40 cells (data not shown).

The main source of superoxide production is the mitochondria. During energy transduction, a small number of electrons "leak" to oxygen prematurely, forming the oxygen free radical superoxide, which has been implicated in the pathophysiology of a variety of diseases [32]. In spite of these implications, superoxide is not highly reactive [33], and it is membrane impermeable, so it is highly compartmentalized within the cell, that is, there is no flux between the pools of matrix and cytoplasmic superoxide [34, 35]. However, more reactive secondary ROS, such as hydrogen peroxide and hydroxyl radicals, are derived from superoxide, and these are able to penetrate biological membranes $[33,35]$. The hydroxyl radical is known to react with all components of the DNA molecule, damaging both the purine and pyrimidine bases, and also the deoxyribose backbone [36]. It therefore seems reasonable that nuclear DNA is damaged more by ROS derived from unscavenged superoxide than by superoxide itself. However, the fact that SOD2-depleted DT40 cells showed no increase in the frequency of SCE indicates that ROS derived from unscavenged, mitochondria-generated superoxide seem to have little impact on the integrity of genomic DNA.

Superoxide is also generated by several enzymes, such as NADPH oxidase, xanthine oxidase, flavoenzymes, and cytochrome P-450, in addition to enzymes of the mitochondrial respiratory chain $[35,37]$. The relatively ubiquitous distribution of SOD1 in the cell seems to indicate that SOD1 scavenges superoxide at the site where it is generated. In this context, it is interesting that the cells expressing NES-hSOD1 showed a relatively high frequency of SCE. This suggests that nuclear SOD1 could function to mitigate DNA lesions caused directly or indirectly by superoxide generated in or near the nucleus. At present, it is not clear how superoxide is generated there, but NADPH oxidase is one candidate. NADPH oxidase produces superoxide in phagocytes, and a significant proportion of the NADPH oxidase subunits in unstimulated cells is present as a fully preassembled and functional ROS-generating complex associated with the intracellular cytoskeleton, particularly in a perinuclear distribution [35]. Furthermore, the highest level of NADPH oxidase complex-dependent superoxide generation has been detected in the nuclei-enriched fraction among several subcellular fractions differentiated by centrifugation [37]. 

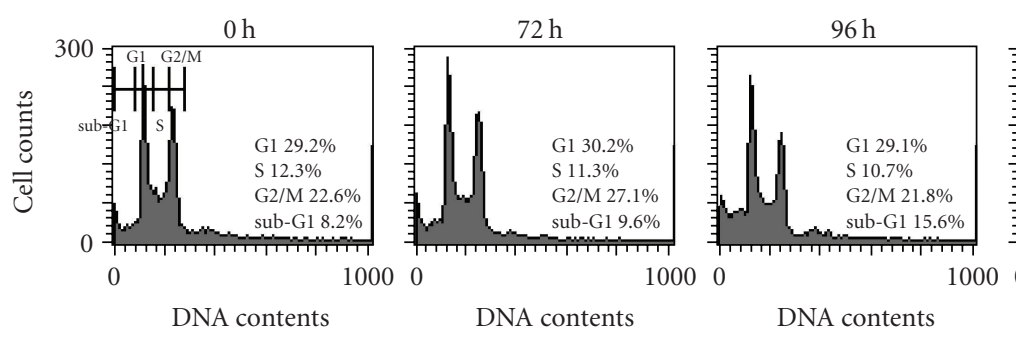

DNA contents

(a)

Hyper
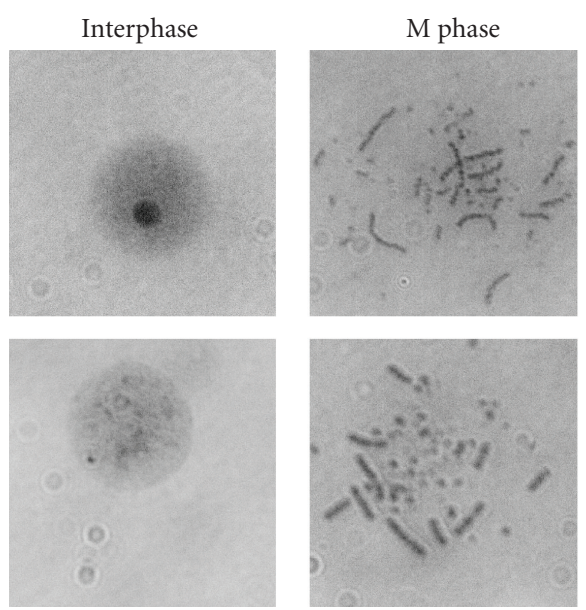

condensation
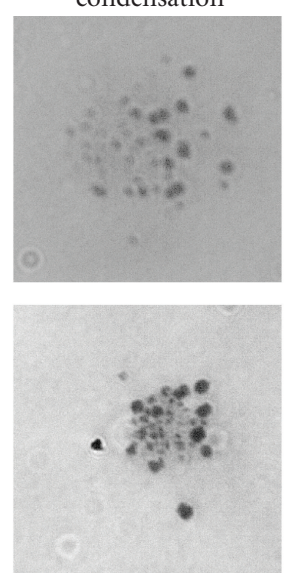

$120 \mathrm{~h}$

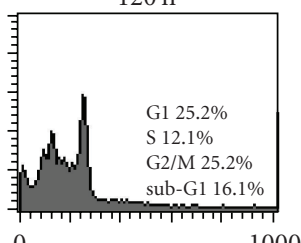

10000

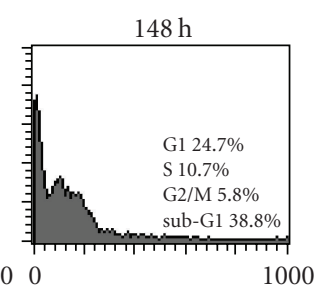

DNA contents

DNA contents

Others
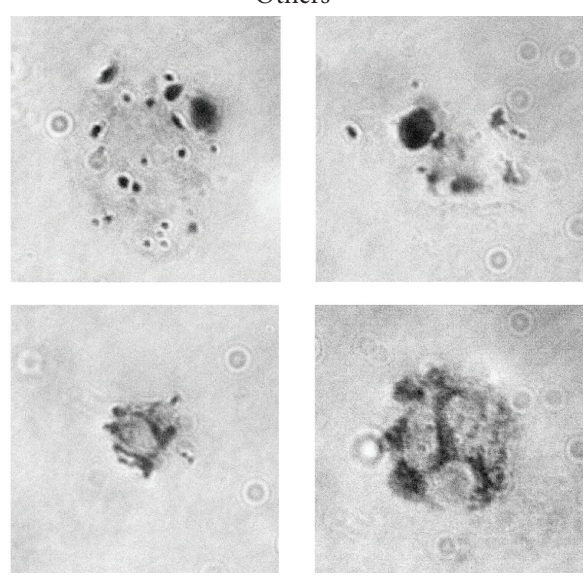

\begin{tabular}{|l|c|c|c|c|}
\hline & \multirow{2}{*}{ Wild-type } & \multicolumn{3}{|c|}{ SOD1 } \\
\cline { 3 - 5 } & & No treatment & Dox $(+) 96 \mathrm{~h}$ & Dox $(+) 128 \mathrm{~h}$ \\
\hline Interphase & 91.3 & 93.5 & 80.1 & 4.1 \\
\hline M phase & 8.2 & 5.6 & 0.2 & 5.1 \\
\hline Hypercondensation & 0 & 0.4 & 15.7 & 5 \\
\hline Others & 0.5 & 0.5 & 26.2 \\
\hline
\end{tabular}

(b)

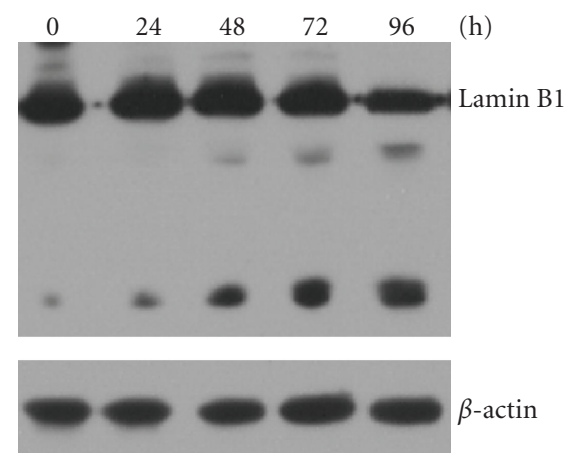

(c)

FIGURE 2: Phenomena appearing after depletion of SOD1. (a) Cell cycle analysis of $S O D 1^{-/-}$cells. Cell cycle was analyzed using flow cytometry. Distribution patterns of asynchronous culture of Dox-treated cells for the indicated timepoints. The percentages of cells in each cell cycle phase and dead cells are shown on the right side of each panel. (b) Categorization of Giemsa-stained cells. Cells not having interphase nucleus, mitotic chromosomes, or hypercondensed chromosomes are classified into others in which apoptotic cells are included. Cells were harvested and treated with $75 \mathrm{mM} \mathrm{KCl}$ and fixed with methanol-acetic acid $(3: 1)$. The cell suspension was dropped onto wet glass slides, air dried, and stained with Giemsa solution (upper row). Percentages of cells exhibiting select phenomena were based on the categorization detailed in the boxes above the micrographs. At least 500 cells were counted in each sample. (c) Western blotting analysis of Lamin B1, with $\beta$-actin used as loading control. 


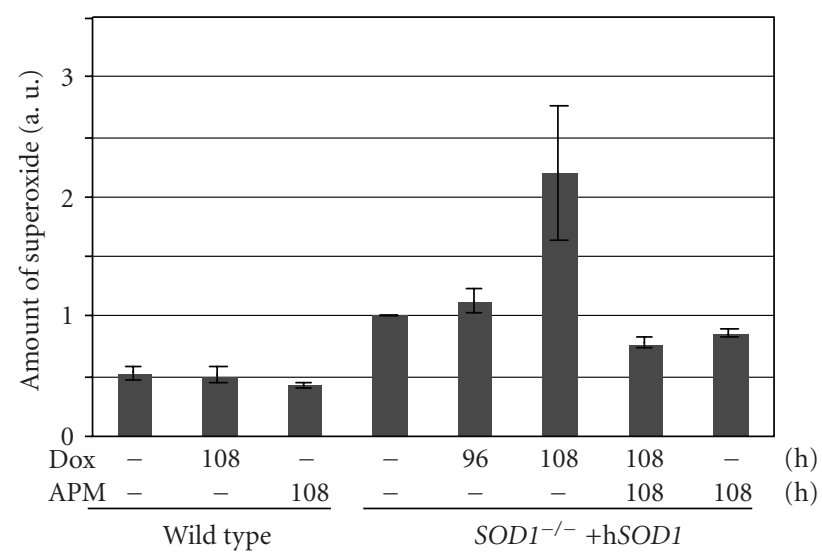

(a)
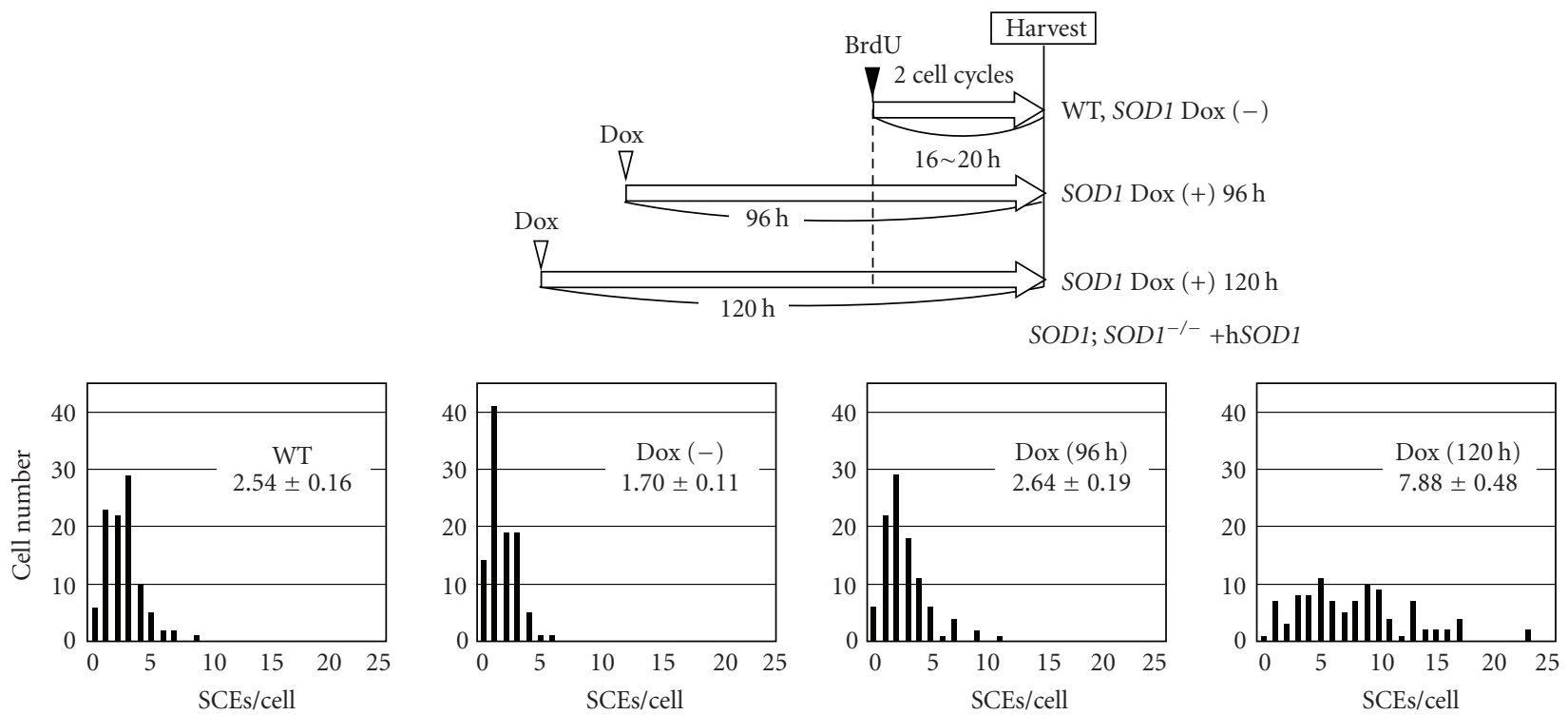

(b)

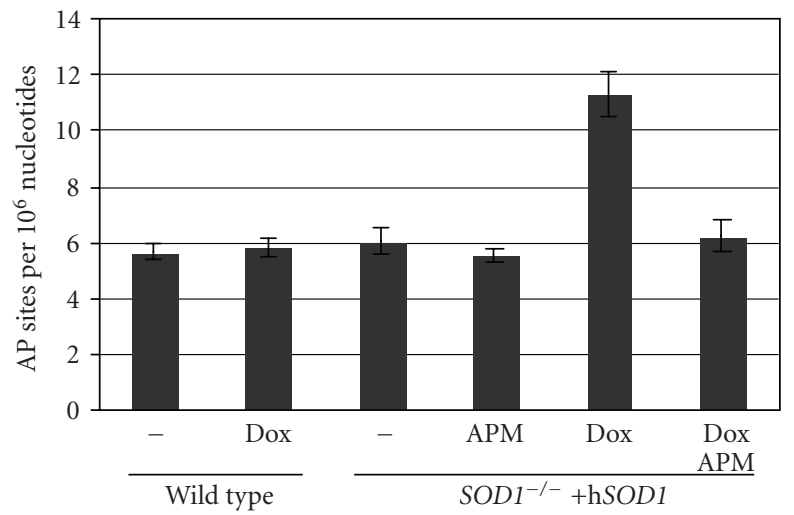

(c)

FIGURE 3: Increases in superoxide, SCE frequency, and AP sites upon depletion of SOD1. (a) Superoxide level. Levels of superoxide were measured with BES-So-AM. The intensity of SOD1 $1^{-/-}+$hSOD1 cells not treated with Dox was used as the standard (a.u.; arbitrary unit =1). Error bars indicate standard errors based on three independent experiments. (b) SCE frequency. Schematic representation of cell treatment is depicted in upper panel. Cells were cultured for two cell cycles in a medium containing BrdU. Histograms represent SCEs in wild-type cells and in SOD1 ${ }^{-/-}$cells treated with Dox for the indicated timepoints. The mean and standard error are shown in the upper right corner. (c) AP sites. Scanning densitometric analysis of slot blots of endogenous AP sites was performed as described previously in [21]. Some cells were treated with Dox and/or APM for 112 hours. Bars indicate standard errors. 

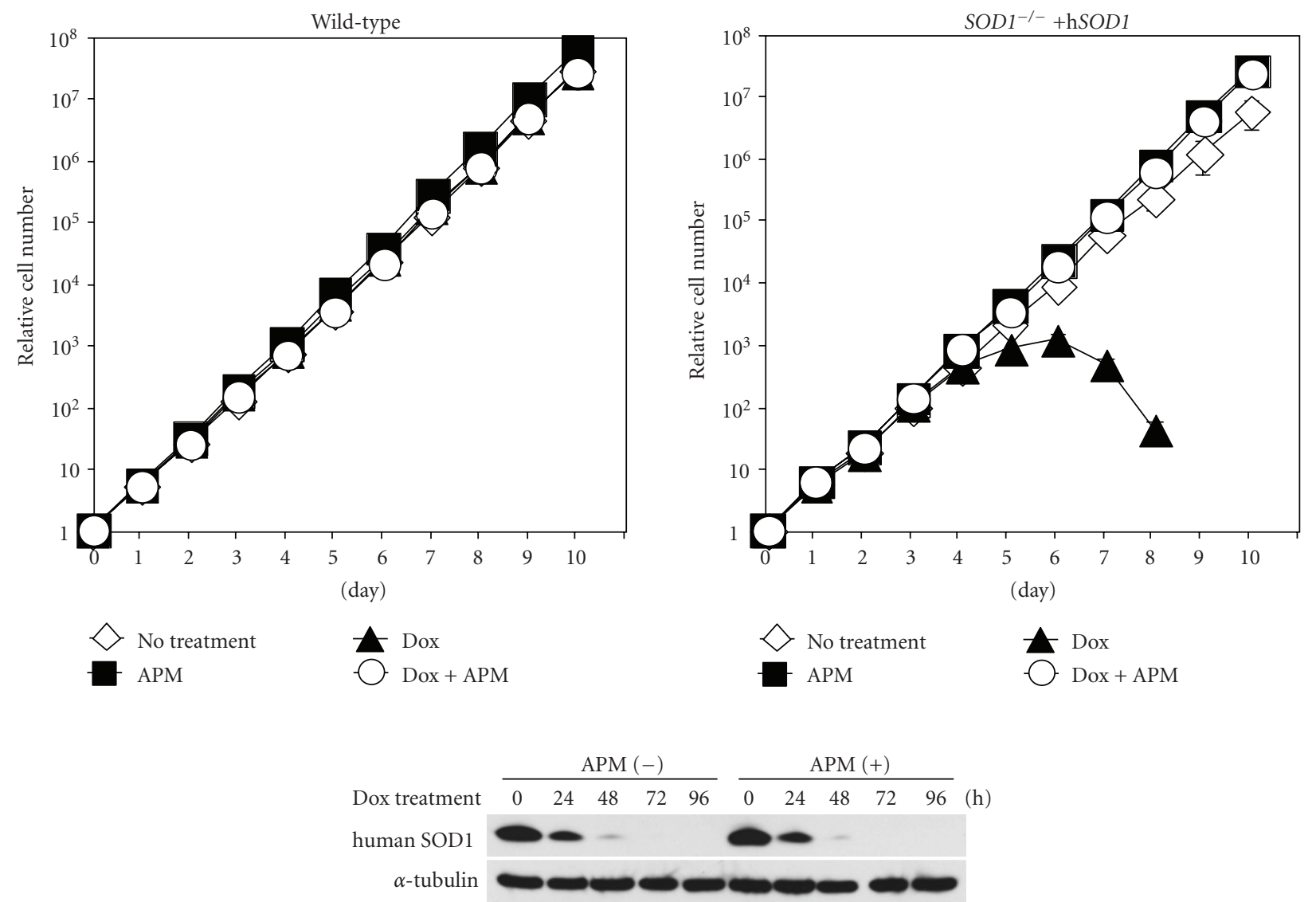

(a)

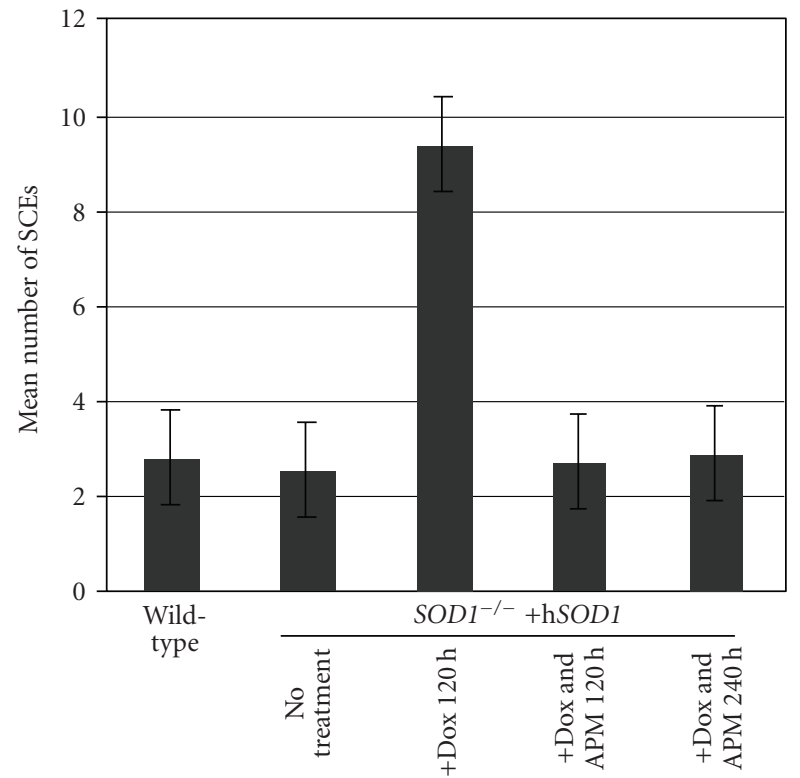

(b)

FIGURE 4: Suppression of lethality and increase in SCE frequency in cells depleted of SOD1 by APM (a) Upper panel: growth curves of cells of the indicated genotypes. Cells were cultured with or without $1 \mu \mathrm{g} / \mathrm{mL}$ Dox and/or $200 \mu \mathrm{M}$ APM. Lower panel: disappearance of hSOD1 was confirmed by western blotting. (b) SCE frequencies of cells treated with Dox and APM for 0, 120, or 240 hours. A total of 100 metaphase cells was counted in each sample. Bars indicate standard errors. 

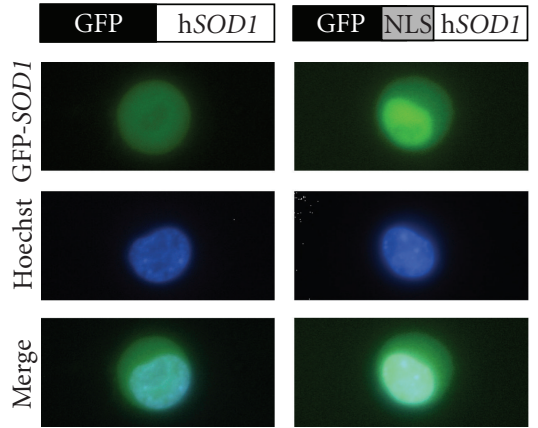

(a)

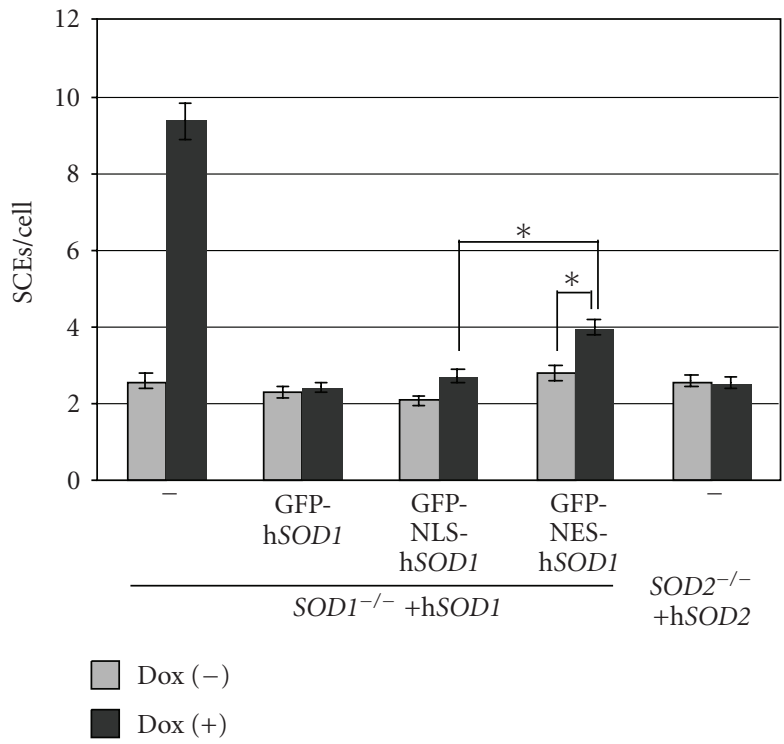

(c)

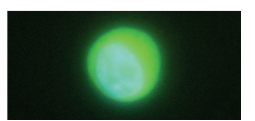

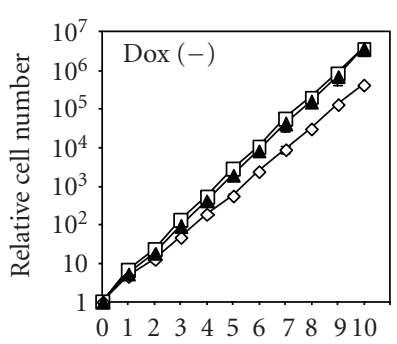

(day)

$S O D 1^{-/-}+\mathrm{hSOD1}$ cell supplemented with

$\rightarrow-$ GFP-hSOD1

$\multimap$ GFP-NLS-hSODl

(b)

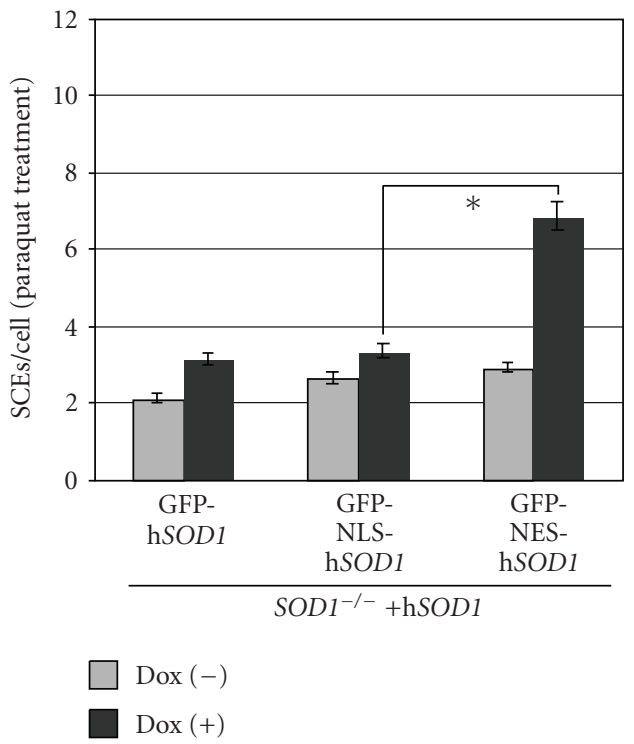

(d)

FIGURE 5: Exclusion of SOD1 from nuclei increases SCE. (a) Distribution of SOD1 with NLS or NES localization signal. Upper panels show the subcellular localization of GFP-hSOD1 with and without localization signals. The middle and lower panels indicate Hoechst staining and merged images, respectively. (b) Growth curves of SOD1 $1^{-1-}+$ hSOD1 cells complemented with indicated hSOD1. Cells were cultured in the presence or absence of $1 \mu \mathrm{g} / \mathrm{mL}$ Dox. (c) SCE frequency. SCE frequencies of SOD $1^{-1-}+\mathrm{hSOD} 1 \mathrm{cells}$ expressing the indicated hSOD1 or those of SOD $2^{-/-}+\mathrm{hSOD} 2$ cells cultured in the presence or absence of $1 \mu \mathrm{g} / \mathrm{mL}$ Dox for 120 hours were measured. Bars indicate standard errors. *; student $t$-test, $P<.01$. (d) SCE frequency in the presence of paraquat. Paraquat was added at a final concentration of $100 \mu \mathrm{M}$ to the culture medium 20 hours prior to harvesting. SCE frequencies of SOD $1^{-/-}+$hSOD1 cells expressing the indicated hSOD1 in the presence or absence of $1 \mu \mathrm{g} / \mathrm{mL}$ Dox for 120 hours were measured. Bars indicate standard errors. *; student $t$-test, $P<.01$.

SOD1 is a very abundant protein in the cell and may play roles other than the dismutation of superoxide. For example, SOD1 interacts with $\mathrm{ER} \alpha$, a ligand-activated transcription factor, and influences the expression of estrogen responsive genes [15]. Therefore, it is conceivable that some of the observed phenotypes of SOD1-depleted cells are caused by depletion of SOD1 protein itself and not by a defect in superoxide dismutase activity. However, this possibility is unlikely, since ascorbic acid suppressed all of the phenotypes of SOD1-depleted cells, including cell lethality.

Although depletion of SOD1 causes DNA lesions, as indicated by increases in SCE frequency and AP sites, the major cause for lethality in SOD1-depleted cells is not the increase in DNA lesions, since the increases in SCE frequency and AP sites are moderate and since NES-SOD1 suppresses lethality. The appearance of "hyper condensed chromatin" suggests hindrance of microtubules formation. Noteworthy, the level of superoxide and SCE frequency increased in SOD1 depleted cell around 108-120 h after addition of Dox (Figures 3(a) and 4(b)). In contrast, apoptotic cells appeared at 96 hours after addition of Dox. We speculate that superoxide level begins to increase earlier than 96 hours after addition of Dox although it is too little to be detected. Since ascorbic acid suppressed the phenotypes observed at 96 hours after addition of Dox, an increase in superoxide even at a low level may influence something more sensitive cellular components other than nuclear genome. Preliminary experiments indicated disordered microtubules construction 
in SOD1-depleted cells (data not shown). The next direction for our study will therefore to address the major cause for the lethality seen in SOD1-depleted cells.

\section{Conclusions}

SOD1 is essential for cell viability, and depletion of SOD1 causes elevated SCE and increased AP sites. Ascorbic acid suppresses the increase in SCE frequency and AP sites in SOD1-depleted cells. Since elevated spontaneous and paraquat-induced SCE is suppressed by nuclear but not cytoplasmic SOD1, this study represents the first evidence that nuclear SOD1 has a role in guarding the genome against oxidative stress. Taken together, these results clearly demonstrate the importance of the nuclear distribution of SOD1 and ascorbic acid in the maintenance of genome stability.

\section{Acknowledgments}

This paper was supported by Grants-in-Aid for Scientific Research and for Scientific Research in Priority Areas from the ministry of Education, Science, Sports, and Culture of Japan. This paper was also supported in part by the US NIEHS P42-ES05948 and P30-ES10126.

\section{References}

[1] T. Finkel and N. J. Holbrook, "Oxidants, oxidative stress and the biology of ageing," Nature, vol. 408, no. 6809, pp. 239-247, 2000.

[2] L. J. Marnett and J. P. Plastaras, "Endogenous DNA damage and mutation," Trends in Genetics, vol. 17, no. 4, pp. 214-221, 2001.

[3] J. M. McCord and I. Fridovich, "Superoxide dismutase. An enzymic function for erythrocuprein (hemocuprein)," Journal of Biological Chemistry, vol. 244, no. 22, pp. 6049-6055, 1969.

[4] I. N. Zelko, T. J. Mariani, and R. J. Folz, "Superoxide dismutase multigene family: a comparison of the CuZn-SOD (SOD1), Mn-SOD (SOD2), and EC-SOD (SOD3) gene structures, evolution, and expression," Free Radical Biology and Medicine, vol. 33, no. 3, pp. 337-349, 2002.

[5] L.-Y. Chang, J. W. Slot, H. J. Geuze, and J. D. Crapo, "Molecular immunocytochemistry of the CuZn superoxide dismutase in rat hepatocytes," Journal of Cell Biology, vol. 107, no. 6 I, pp. 2169-2179, 1988.

[6] J. D. Crapo, T. Oury, C. Rabouille, J. W. Slot, and L.-Y. Chang, "Copper,zinc superoxide dismutase is primarily a cytosolic protein in human cells," Proceedings of the National Academy of Sciences of the United States of America, vol. 89, no. 21, pp. 10405-10409, 1992.

[7] L. A. Sturtz, K. Diekert, L. T. Jensen, R. Lill, and V. C. Culotta, "A fraction of yeast $\mathrm{Cu}, \mathrm{Zn}$-superoxide dismutase and its metallochaperone, CCS, localize to the intermembrane space of mitochondria. A physiological role for SOD1 in guarding against mitochondrial oxidative damage," Journal of Biological Chemistry, vol. 276, no. 41, pp. 38084-38089, 2001.

[8] R. A. Weisiger and I. Fridovich, "Superoxide dismutase. Organelle specificity," Journal of Biological Chemistry, vol. 248, no. 10 , pp. 3582-3592, 1973.
[9] R. A. Weisiger and I. Fridovich, "Mitochondrial superoxide dismutase. Site of synthesis and intramitochondrial localization," Journal of Biological Chemistry, vol. 248, no. 13, pp. 4793-4796, 1973.

[10] S. L. Marklund, E. Holme, and L. Hellner, "Superoxide dismutase in extracellular fluids," Clinica Chimica Acta, vol. 126, no. 1, pp. 41-51, 1982.

[11] R. M. Lebovitz, H. Zhang, H. Vogel et al., "Neurodegeneration, myocardial injury, and perinatal death in mitochondrial superoxide dismutase-deficient mice," Proceedings of the National Academy of Sciences of the United States of America, vol. 93, no. 18, pp. 9782-9787, 1996.

[12] Y. Li, T.-T. Huang, E. J. Carlson et al., "Dilated cardiomyopathy and neonatal lethality in mutant mice lacking manganese superoxide dismutase," Nature Genetics, vol. 11, no. 4, pp. 376381, 1995.

[13] S. Takada, E. Inoue, K. Tano et al., "Generation and characterization of cells that can be conditionally depleted of mitochondrial SOD2," Biochemical and Biophysical Research Communications, vol. 379, no. 2, pp. 233-238, 2009.

[14] R. J. Albertini, D. Anderson, G. R. Douglas et al., "IPCS guidelines for the monitoring of genotoxic effects of carcinogens in humans," Mutation Research, vol. 463, no. 2, pp. 111-172, 2000.

[15] A. K. Rao, Y. S. Ziegler, I. X. McLeod, J. R. Yates, and A. M. Nardulli, "Effects of $\mathrm{Cu} / \mathrm{Zn}$ superoxide dismutase on estrogen responsiveness and oxidative stress in human breast cancer cells," Molecular Endocrinology, vol. 22, no. 5, pp. 1113-1124, 2008.

[16] R. A. Busuttil, A. M. Garcia, C. Cabrera et al., "Organ-specific increase in mutation accumulation and apoptosis rate in CuZn-superoxide dismutase-deficient mice," Cancer Research, vol. 65, no. 24, pp. 11271-11275, 2005.

[17] S. Elchuri, T. D. Oberley, W. Qi et al., "CuZnSOD deficiency leads to persistent and widespread oxidative damage and hepatocarcinogenesis later in life," Oncogene, vol. 24, no. 3, pp. 367-380, 2005.

[18] M. Gossen and H. Bujard, "Tight control of gene expression in mammalian cells by tetracycline- responsive promoters," Proceedings of the National Academy of Sciences of the United States of America, vol. 89, no. 12, pp. 5547-5551, 1992.

[19] Y. Takami and T. Nakayama, "N-terminal region, C-terminal region, nuclear export signal, and deacetylation activity of histone deacetylase-3 are essential for the viability of the DT40 chicken B cell line," Journal of Biological Chemistry, vol. 275, no. 21, pp. 16191-16201, 2000.

[20] H. Maeda, K. Yamamoto, I. Kohno et al., "Design of a practical fluorescent probe for superoxide based on protectiondeprotection chemistry of fluoresceins with benzenesulfonyl protecting groups," Chemistry, vol. 13, no. 7, pp. 1946-1954, 2007.

[21] P. D. Chastain 2nd, J. Nakamura, J. Swenberg, and D. Kaufman, "Nonrandom AP site distribution in highly proliferative cells," FASEB Journal, vol. 20, no. 14, pp. 2612-2614, 2006.

[22] T.-T. Huang, M. Yasunami, E. J. Carlson et al., "Superoxidemediated cytotoxicity in superoxide dismutase-deficient fetal fibroblasts," Archives of Biochemistry and Biophysics, vol. 344, no. 2, pp. 424-432, 1997.

[23] D. F. Hudson, P. Vagnarelli, R. Gassmann, and W. C. Earnshaw, "Condensin is required for nonhistone protein assembly and structural integrity of vertebrate mitotic chromosomes," Developmental Cell, vol. 5, no. 2, pp. 323-336, 2003.

[24] E. Sonoda, M. S. Sasaki, C. Morrison, Y. Yamaguchi-Iwai, M. Takata, and S. Takeda, "Sister chromatid exchanges are 
mediated by homologous recombination in vertebrate cells," Molecular and Cellular Biology, vol. 19, no. 7, pp. 5166-5169, 1999.

[25] M. Otsuki, M. Seki, E. Inoue et al., "Analyses of functional interaction between RECQL1, RECQL5, and BLM which physically interact with DNA topoisomerase III $\alpha$," Biochimica et Biophysica Acta, vol. 1782, no. 2, pp. 75-81, 2008.

[26] J. Nakamura and J. A. Swenberg, "Endogenous apurinic/ apyrimidinic sites in genomic DNA of mammalian tissues," Cancer Research, vol. 59, no. 11, pp. 2522-2526, 1999.

[27] S. Koyama, S. Kodama, K. Suzuki, T. Matsumoto, T. Miyazaki, and M. Watanabe, "Radiation-induced long-lived radicals which cause mutation and transformation," Mutation Research, vol. 421, no. 1, pp. 45-54, 1998.

[28] T. Harada, G. Kashino, K. Suzuki, N. Matsuda, S. Kodama, and M. Watanabe, "Different involvement of radical species in irradiated and bystander cells," International Journal of Radiation Biology, vol. 84, no. 10, pp. 809-814, 2008.

[29] M. M. Matzuk, L. Dionne, Q. Guo, T. R. Kumar, and R. M. Lebovitz, "Ovarian function in superoxide dismutase 1 and 2 knockout mice," Endocrinology, vol. 139, no. 9, pp. 4008-4011, 1998.

[30] S. Elchuri, T. D. Oberley, W. Qi et al., "CuZnSOD deficiency leads to persistent and widespread oxidative damage and hepatocarcinogenesis later in life," Oncogene, vol. 24, no. 3, pp. 367-380, 2005.

[31] I. B. Chatterjee, "Evolution and the biosynthesis of ascorbic acid," Science, vol. 182, no. 4118, pp. 1271-1272, 1973.

[32] M. Valko, D. Leibfritz, J. Moncol, M. T. D. Cronin, M. Mazur, and J. Telser, "Free radicals and antioxidants in normal physiological functions and human disease," International Journal of Biochemistry and Cell Biology, vol. 39, no. 1, pp. 4484, 2007.

[33] J. Nordberg and E. S. J. Arnér, "Reactive oxygen species, antioxidants, and the mammalian thioredoxin system," Free Radical Biology and Medicine, vol. 31, no. 11, pp. 1287-1312, 2001.

[34] F. Missirlis, J. Hu, K. Kirby, A. J. Hilliker, T. A. Rouault, and J. P. Phillips, "Compartment-specific protection of ironsulfur proteins by superoxide dismutase," Journal of Biological Chemistry, vol. 278, no. 48, pp. 47365-47369, 2003.

[35] J.-M. Li and A. M. Shah, "Endothelial cell superoxide generation: regulation and relevance for cardiovascular pathophysiology," American Journal of Physiology, vol. 287, no. 5, pp. R1014-R1030, 2004.

[36] B. Halliwell and J. M. C. Gutteridge, Free Radicals in Biology and Medicine, Oxford University Press, Oxford, UK, 3rd edition, 1999.

[37] J.-M. Li and A. M. Shah, "Intracellular localization and preassembly of the NADPH oxidase complex in cultured endothelial cells," Journal of Biological Chemistry, vol. 277, no. 22, pp. 19952-19960, 2002. 

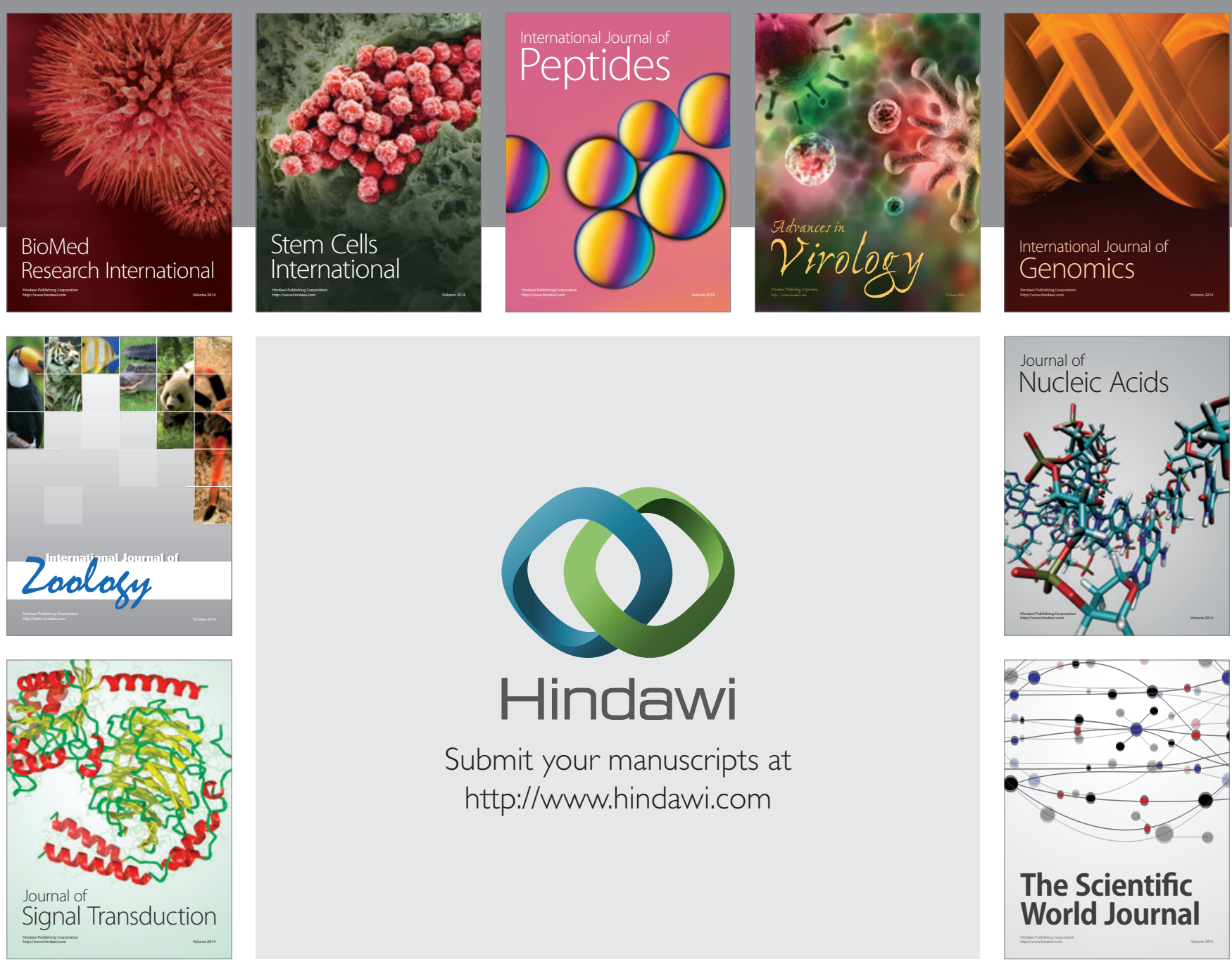

Submit your manuscripts at

http://www.hindawi.com
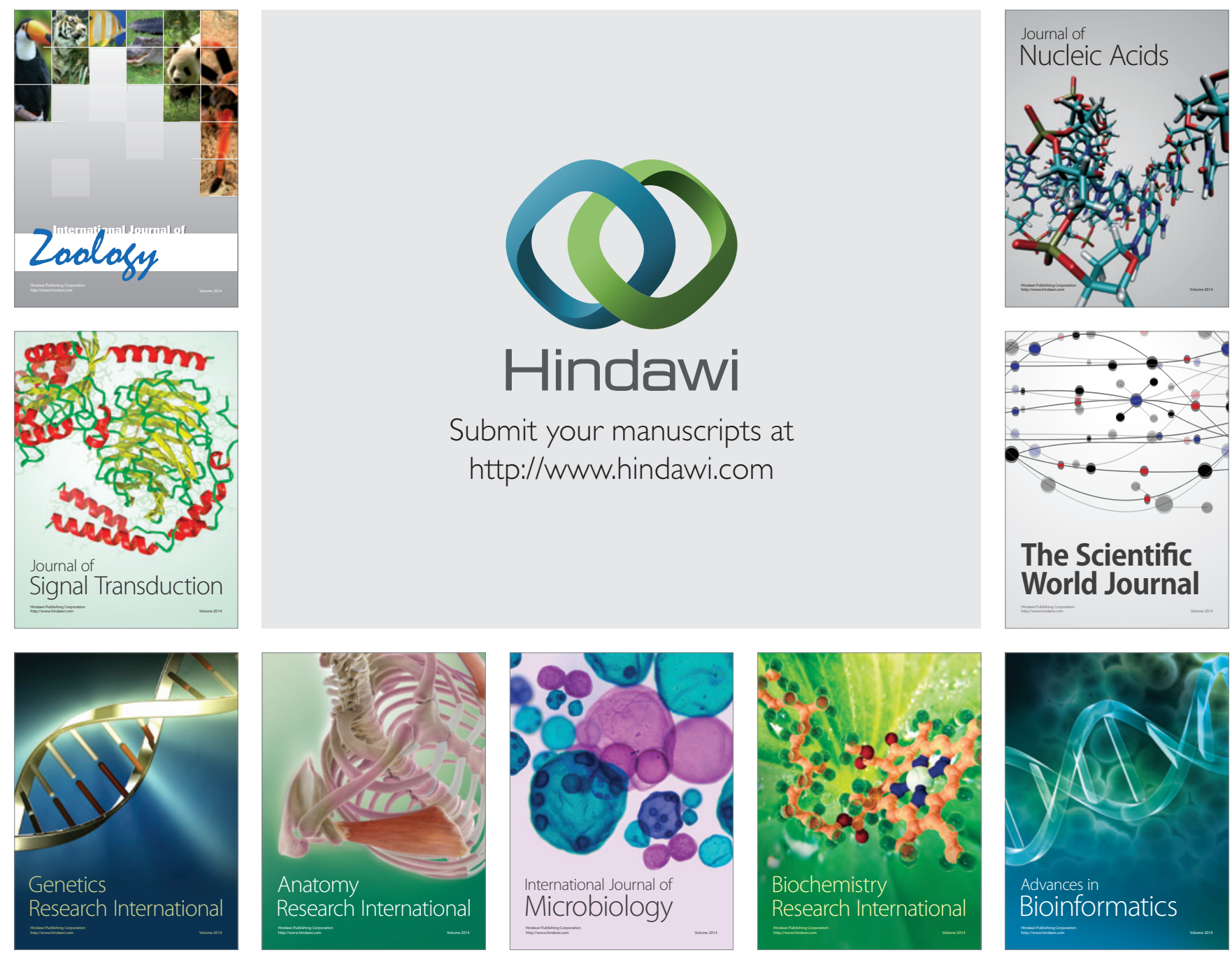

The Scientific World Journal
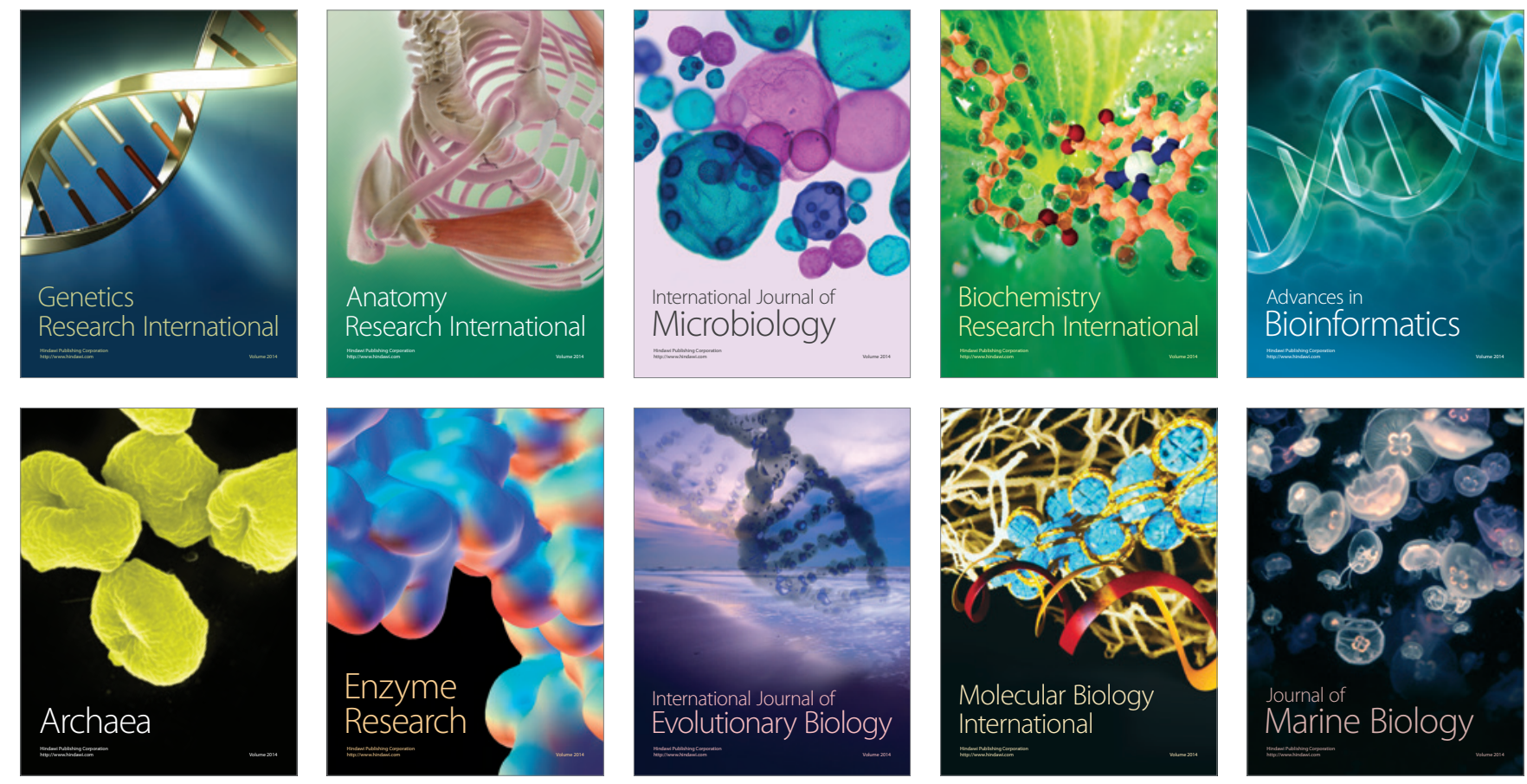